\title{
ASSOCIACCÕES PLUTÔNICAS DO COMPLEXO GRANITÓIDE SOCORRO (ESTADOS DE SÃO PAULO E MINAS GERAIS, SE BRASIL)
}

\author{
ANTÓNIO C. ARTUR*, EBERHARD WERNICK*, PAUL K. HÔRMANN** $\mathrm{e}$ \\ KLAUS WEBER-DIEFENBACH****
}

\begin{abstract}
PLUTONIC ASSOCIATIONS OF THE SOCORRO GRANITOID COMPLEX (STATES OF SÃO PAULO AND MINAS GERAIS, SE BRAZIL). The pluriserial Socorro granitoid complex is located in an área highly affected by the convergence and collision of the Paraná and São Francisco plates during the Late Precambrian. The complex is affected by the tectonic periods of thrust, transcurrent and normal faulting which on regional scale express this convergence and collision. The complex comprises four distinct plutonic associations: Socorro I (calc-alkaline, medium/high K), Socorro II (calc-alkaline, high K), Nazaré Paulista (crustal, garnet bearing) and Piracaia (alkaline, polassic). They represem the main regional magmatic activities ocurred roughly between 650 and $550 \mathrm{Ma}$ ago. The Socorro $\mathrm{I}$ association can be considered as linked with the convergent stage and the Nazare Paulista association with the collisional stage of the plates. The Socorro II association is the magmatic product of the late-collision uplift and the Piracaia association is linked with the post-collision relaxing stage. The periods of emplacement of the four plutonic associations show partial temporal overlaps which reflects the gradual transitions between the successive stages in the regional geodynamic evolution.
\end{abstract}

Keywords: Granite, tectonic, pluriserial complexos.

\begin{abstract}
RESUMO O Complexo Granitóide Plurisserial Socorro situa-se na área de influência interna da convergência e colisão das placas São Francisco e Paraná no Pré-Cambriano Superior. O complexo é afetado pêlos períodos tectônicos de cavalgamento, transcorrência e de falhamentos normais que, na região, expressam o fim da convergência e colisão entre estas placas. O complexo compreende quatro associações plutônicas distintas: Socorro I (cálcio-alcalina, médio a alto K), Socorro II (cálcio-alcalina, alto K), Nazaré Paulista (de origem crustal, granatífero) e Piracaia (alcalino potássico). Eles representam atividades magmáticas ocorridas no intervalo entre cerca de 650 e $500 \mathrm{Ma}$ atrás. A Associação Socorro I pode ser vinculada com o período de convergência e a Associação Nazaré Paulista com o período de colisão continental. A Associação Socorro II se vincula com o período de soerguimento tardi-colisional e a Associação Piracaia com a fase de relaxamento póscolisional. Os períodos de colocação das associações magmáticas revelam superposição temporal parcial retratando a gradual transição entre os diversos estágios da evolução geodinâmica regional.
\end{abstract}

Palavras-chave: Granito, tectônica, complexos plurisseriais.

INTRODUÇAO Complexos plurisseriais são constituídos por associações rochosas referíveis a distintas séries magmáticas. Podem resultar, basicamente, de quatro processos distintos: 1. da coalescência de distintos magmatismos ao longo de zonas de subducção muito inclinadas; 2. da superposição espacial dos magmatismos resultantes de processos magmatogênicos que atuam simultaneamente sobre distintos protólitos à diferentes profundidades; 3 . agregação espacial de distintos magmatismos frutos da variação nas condições geodinâmicas numa certa área com o decorrer do tempo; 4. uma complexa combinação dos casos anteriores.

Na porção ocidental do Complexo Granitóide Socorro (Pré-Cambriano Superior, Estados de São Paulo e Minas Gerais), ocorre a superposição espacial de quatro associações plutônicas distintas (Fig. 1): 1. Associação Nazaré Paulista, granatífera e de origem crustal; 2. Associação Socorro I, cálcio-alcalina de médios a altos teores de $\mathrm{K}_{2} \mathrm{O} ; 3$. Associação Socorro II, cálcio-alcalina de altos teores de $\mathrm{K}_{2} \mathrm{O}$; e 4. Associação Piracaia, alcalina transicional.

Neste trabalho, os autores revisam de modo integrado estas quatro associações sob aspectos petrográfico e químico, apresentam novos dados químicos (30 análises) para a Associação Piracaia, discutem a sequência de sua colocação e interpretam o seu significado sob o aspecto geodinâmico.
ASPECTOS TECTÔNICOS O Complexo Granitóide Socorro situa-se na zona de convergência oblíqua e posterior colisão entre os blocos São Francisco e Paraná (Soares et al. 1990) ocorrida durante o Pré-Cambriano Superior, tendo aquele mergulhado sob este (Davino, 1979). Durante a colisão ocorreu um intenso imbricamento tectônico, devido a superposição de três períodos de deformação com caracteristicas distintas:

1. um período inicial de cavalgamento (Wernick 1967 , Campos Neto et al. 1984a, Artur 1988, Wernick 1990, Soares et al. 1990, Zanardo 1992). Na região entre Atibaia e Extrema, baseado na intensidade das deformações, no grau de recristalização e nas fácies metamórficas associadas, Artur et al. (1991a) reconheceram três fases sucessivas de cavalgamentos, denominadas de "cedo", "sin" e "tardi" em relação à colisão continental (Fig. 6);

2. um período de falhamentos transcorrentes ao qual se associam amplos movimentos de blocos crustais (Wernick et al 1988b, Artur 1988). Soares et al (1990) ressaltam a longa duração deste período (de sin- a tardi-colisional) e sua ampla distribuição espacial (as falhas cortam o embasamento cristalino dos Estados de Minas Gerais, São Paulo e Paraná), e Artur et al (1991a) a dividem em três fases denominadas de "cedo", "sin" e "tardi" em relação à colisão continental (Fig. 6);

\footnotetext{
* Departamento de Petrologia e Metalogenia, Instituto de Geociências e Ciências Exalas, Universidade Estadual Paulista, Caixa Postal 178, CEP 13500-970, Rio Claro, SP, Brasil, FAX (0195) 249644

** Mineralogisch-Petrographisches Institui und Museuni, Christian-Albrechls Universitat, Ludewig-Meyn Slrasse 10, D-24098 - Kiel 1, Alemanha *** Institui für Allgemeine und Angewandte Geologie, Luisenstrasse 37, D-8000, München 2, Alemanha
} 


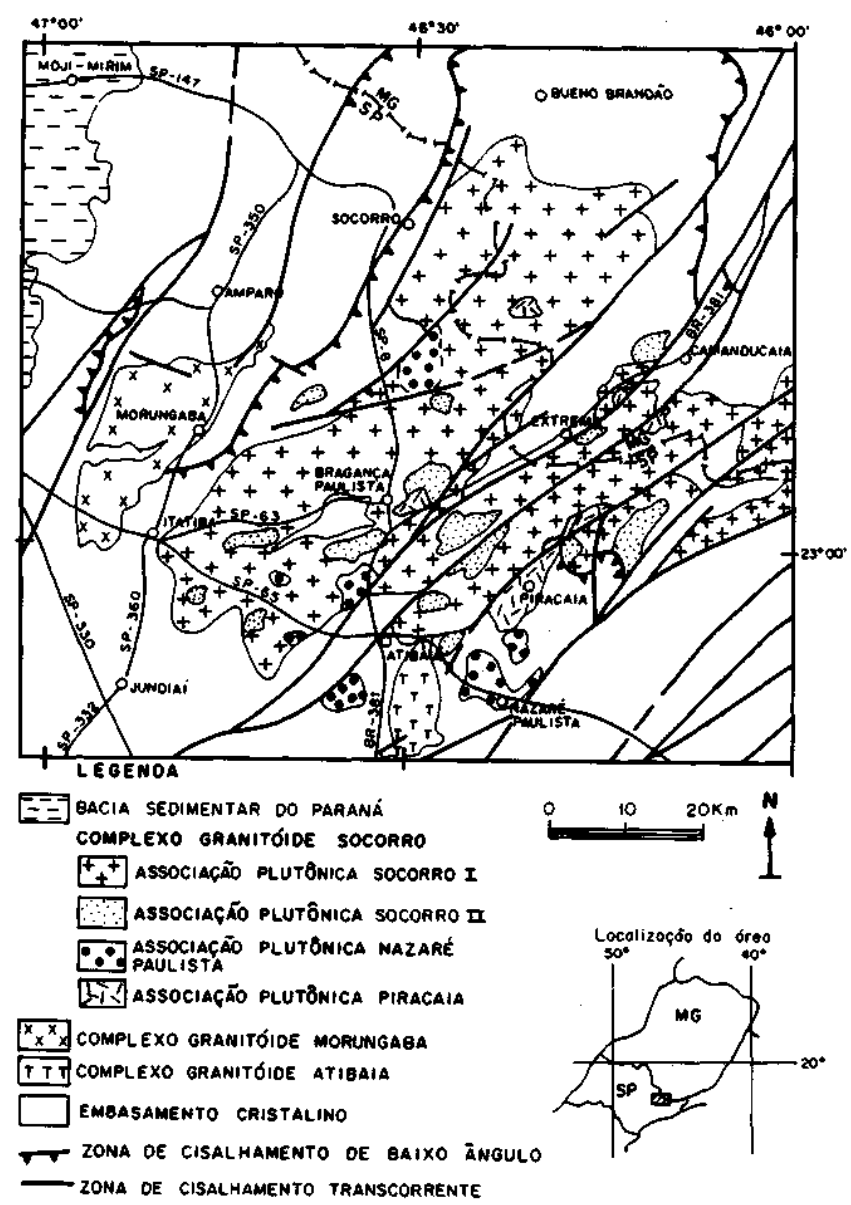

Figura 1 - Estruturação e associações plutônicas do Complexo Granitóide Socorro (Estados de São Paulo e Minas Gerais)

Figure 1 - Magmatic architecture and plutonic associations of the Socorro Granitoid Complex (States of São Paulo and Minas Gerais)

3. um período final de falhas normais seguidamente reativadas (Artur et al 1991a).

ASSOCIAÇÕES MAGMÁTICAS O Complexo Granitóide Socorro compreende quatro associações plutônicas distintas, aqui denominadas de Socorro I, Socorro II, Piracaia e Nazaré Paulista. Suas variações químicas de elementos maiores e menores constam na figura 2 e são baseadas nos seguintes dados químicos:

Socorro I - Wernick et al. (1984a, b), Campos Neto et al, (1984b), Artur et al (1991b).

Socorro II- Wernick et al (1984a, b), Campos Neto et al. (1984b), Artur et al (1991b).

Piracaia - Campos Neto et al (1983), Janasi (1986), Artur et al (1991b) e mais 30 análises aqui apresentadas.

Nazaré Paulista - Campos Neto et al (1984b), Wernick et al (1987).

Associação Socorro l Corresponde a uma suíte granitóide mesozonal, constituída essencialmente por sienogranitos e monzogranitos porfiróides ao lado de subordinados granodioritos, quartzo monzonitos e quartzo monzodioritos contendo plagioclásio, microclínio, quartzo, hornblenda, biotita, além de opacos, titanita, zircão e apatita, configurando mineralogia tipicamente cálcio-alcalina. As variações composicionais do magmatismo Socorro I ocorrem tanto por uma variação da taxa de megacristais numa matriz de composição constante quanto pela variação na

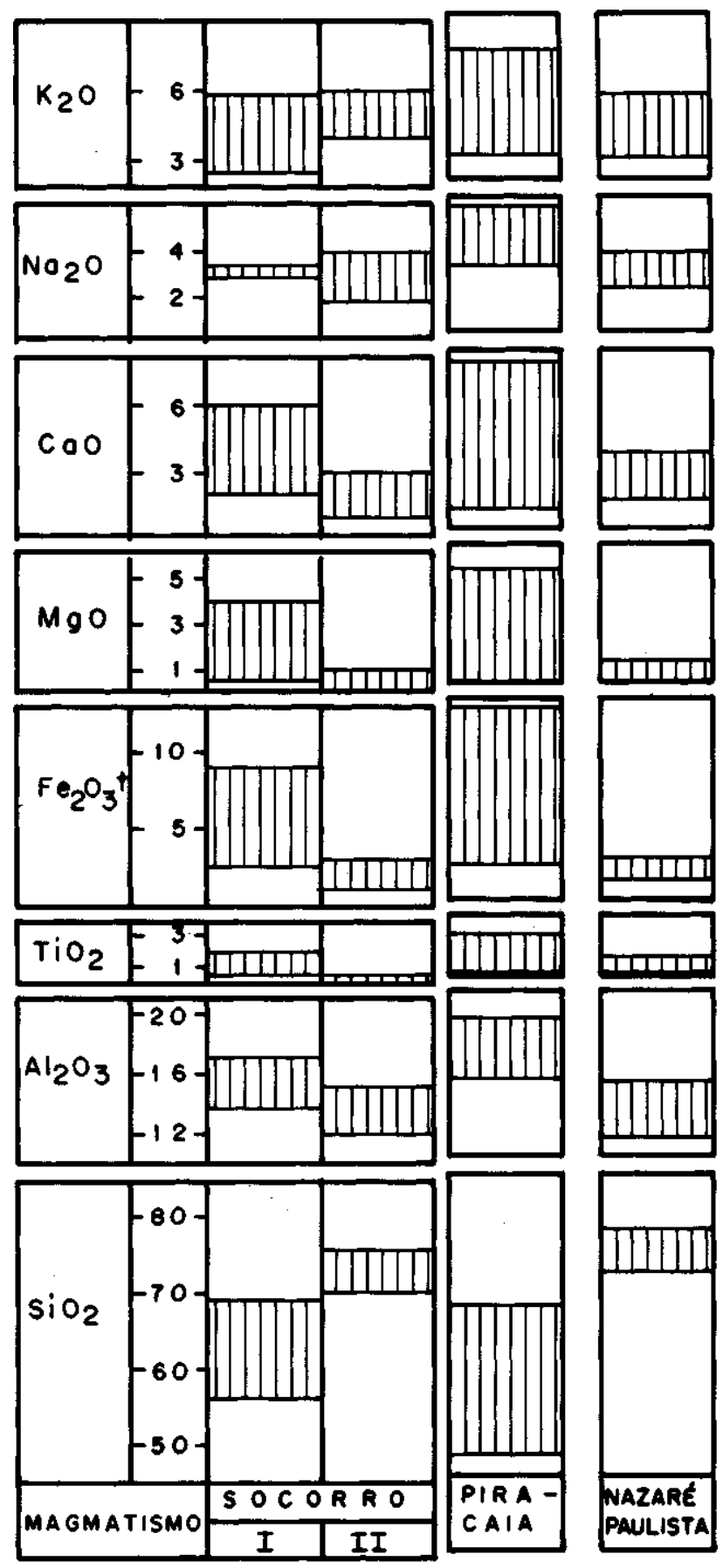

Figura 2 - Variação

química das associações plutônicas

Socorro I, Socorro II, Piracaia e Nazaré Paulista

Figure 2 - Chemical variation of the plutonic associations Socorro I, Socorro II, Piracaia e Nazaré Paulista

composição da matriz mantendo-se a taxa de megacristais aproximadamente constante ou, ainda, pela associação simultânea dos dois parâmetros considerados. São comuns estruturas de fluxo, enclaves microgranulares máficos e bandamentos dados pelo enriquecimento e empobrecimento local de megacristais em leitos subparalelos com espessuras e persistência lateral variada. Wernick et al. (1984b), baseados em dados químicos (elementos maiores, traços e de terras raras) para rochas da região entre Socorro (SP), Pedra Bela (SP), Munhoz (MG) e Bragança Paulista (SP) caracterizaram a natureza cálcio-alcalina da Associação Socorro I, feição confirmada por análises químicas (Wernick et al. 1984a) de parte de sua mineralogia (anfibólio, biotita, 
plagioclásio, feldspato alcalino, ilmenita). A tipologia de zircão (Wernick \& Galembeck 1986, Wernick et al 1988b) caracteriza a Associação Socorro I como pertencente à série cálcio-alcalina de alta temperatura na classificação de Pupin (1980). Dados modais para as rochas da região entre Atibaia (SP) e Extrema (MG) constam em Artur et al. (1991b). Rochas, em parte, equivalentes às aqui descritas foram denominadas, por Campos Neto et al. (1984b), de Suíte Bragança Paulista.

Os diagramas das figuras 3,4 e 5 expressam algumas características químicas da Associação Plutônica Socorro $\mathrm{I}$ por meio dos diagramas $\mathrm{SiO}_{2}$ versus $\left(\mathrm{K}_{2} \mathrm{O}+\mathrm{Na}_{2} \mathrm{O}\right)$, $\mathrm{SiO}_{2}$ versus $\mathrm{K}_{2} \mathrm{O}, \mathrm{Na}_{2} \mathrm{O}$ versus $\mathrm{K}_{2} \mathrm{O}, \mathrm{R}_{1}$, versus $\mathrm{R}_{2}$ e CaO:
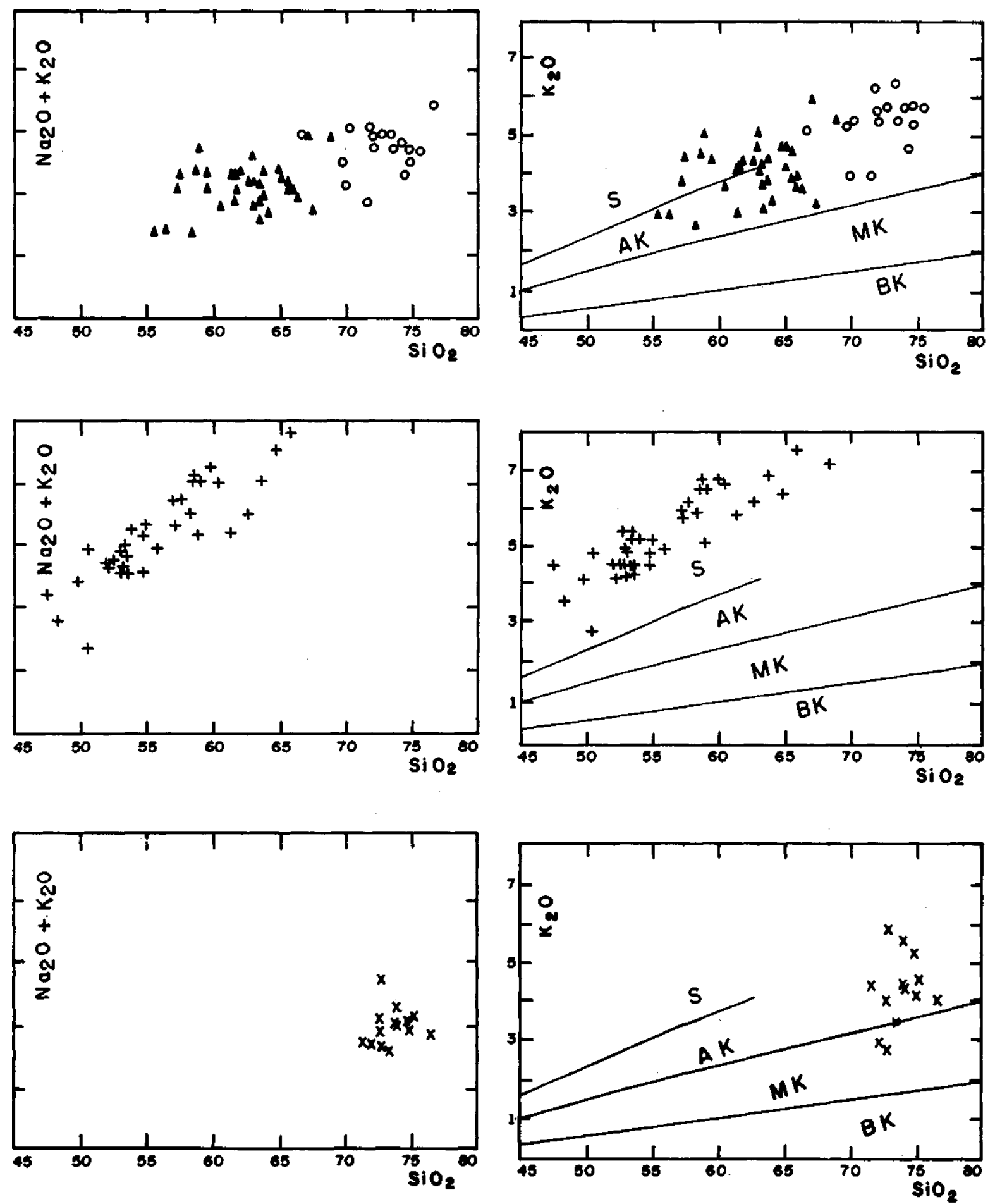

( A )

(B)

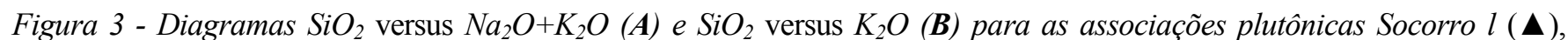
Socorro II (o), Piracaia (+) e Nazaré Paulista (x). Em (B), BK = baixo potássio; $\boldsymbol{M K}=$ médio potássio; $\boldsymbol{A K}=$ alto potássio; $\boldsymbol{S}=$ shoshonítico. Divisões segundo Peccerillo \& Taylor (1976)

Figure $3-\mathrm{SiO}_{2}$ versus $\left(\mathrm{Na}_{2} \mathrm{O}+\mathrm{K}_{2} \mathrm{O}\right)$ diagram $(\mathbf{A})$ and $\mathrm{SiO}_{2}$ versus $\mathrm{K}_{2} \mathrm{O}$ diagram $(\mathbf{B})$ for the plutonic associations Socorro I $(\boldsymbol{\Delta})$, Socorro II (o), Piracaia $(+)$ and Nazaré Paulista (x). In (B), BK = low potash; $\mathbf{M K}=$ médium (or normal) potash; $\mathbf{A K}=$ high potash; $\mathbf{S}=$ shoshonitic. Boundaries after Peccerillo \& Taylor (1976) 
(A)
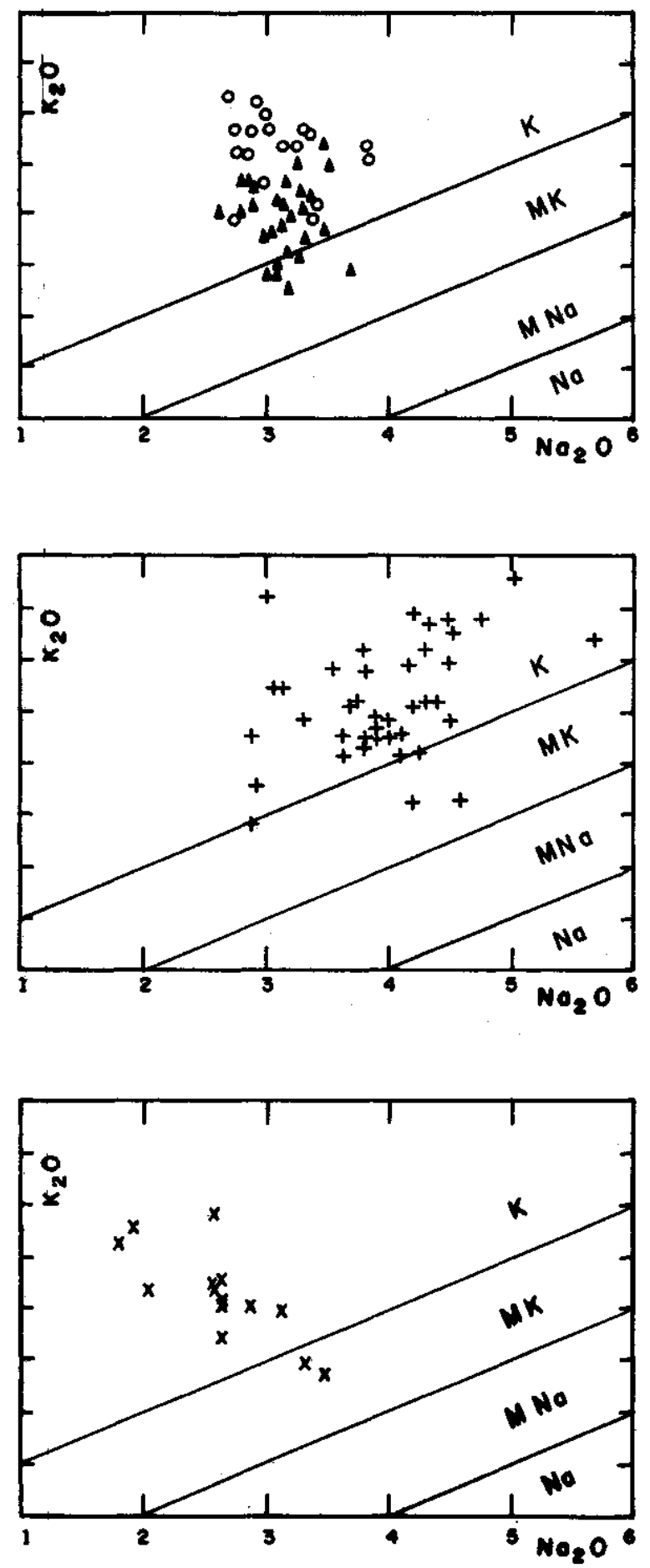

(B)
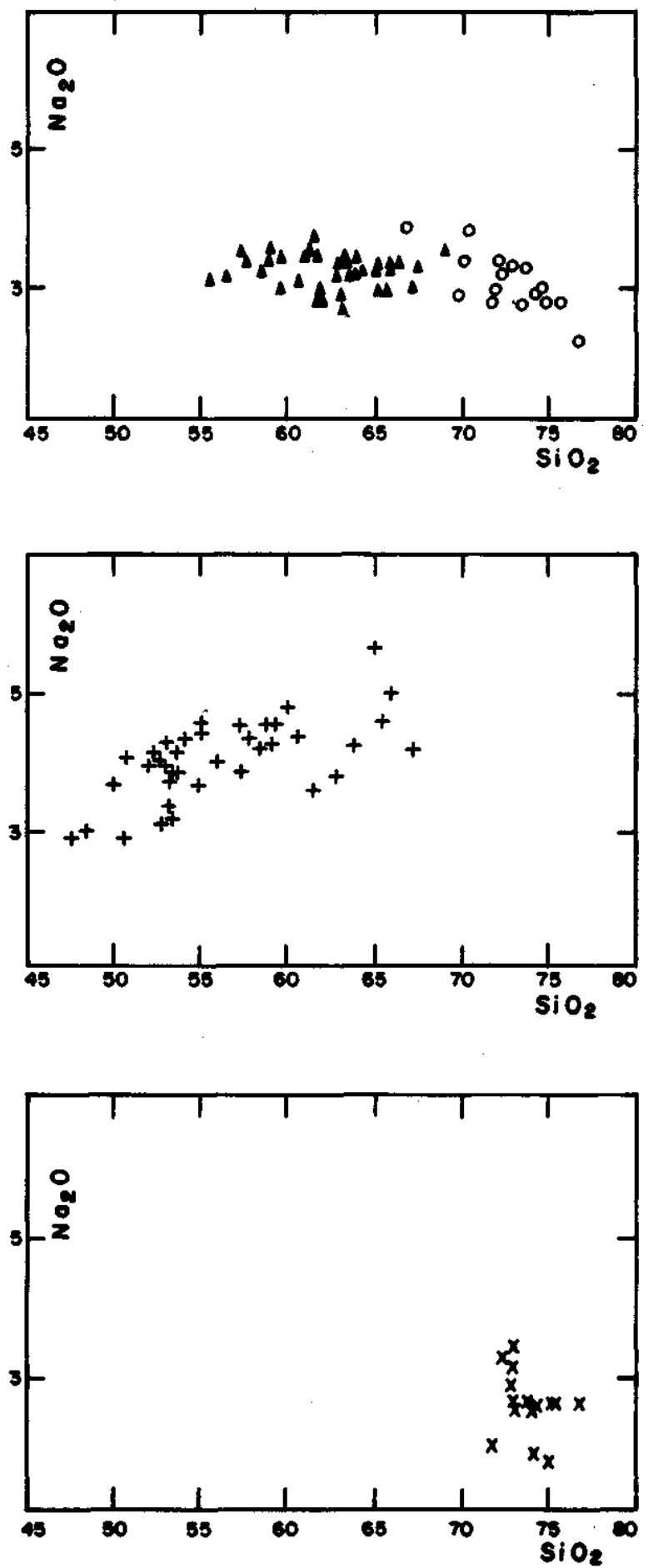

Figura 4 -Diagramas $\mathrm{Na}_{2} \mathrm{O}$ versus $\mathrm{K}_{2} \mathrm{O}(\boldsymbol{A})$ e $\mathrm{SiO}_{2}$ versus $\mathrm{Na}_{2} \mathrm{O}$ (B) para as associaçõesplutônicas Socorro l (4), Socorro II (o), Piracaia (+) e Nazaré Paulista (x). Em (A), $\mathbf{N a}=$ rochas sádicas; $\mathbf{M N a}=$ rochas sódio-potássicas ou mediamente sádicas; $\boldsymbol{M K}=$ rochas potássio-sódicas ou mediamente potássicas; $\boldsymbol{K}=$ rochas potássicas. Divisóes segundo recomendação da IUGS em Le Maitre (1989)

Figure 4 - Na2O versus $\mathrm{K}_{2} \mathrm{O}$ diagram $(\mathbf{A})$ and $\mathrm{SiO}_{2}$ versus $\mathrm{Na}_{2} \mathrm{O}$ diagram $(\mathbf{B})$ for the plutonic associations Socorro I ( $\boldsymbol{\Delta}$ ), Socorro II (o), Piracaia (+) and Nazaré Paulista (x). In (A), Na = sodic rocks; $\mathbf{M N a}=$ sodic-potassic (or mildly sodic) rocks; $\mathbf{M K}=$ potassic-sodic (or mildly potassic) rocks; $\mathbf{K}=$ potassic rocks. Boundaries following IUGS recommendation in Le Maitre (1989)

$\mathrm{K}_{2} \mathrm{O}: \mathrm{Na}_{2} \mathrm{O}$. O último diagrama, assim como o diagrama $\mathrm{R}_{1}$ versus $\mathrm{R}_{2}$, confirmam a natureza cálcio-alcalina da associação plutônica considerada como indicado por sua mineralogia, fato este reforçado pelo diagrama $\mathrm{SiO}_{2}$ versus $\mathrm{Na}_{2} \mathrm{O}$, que mostra os valores aproximadamente constantes de $\mathrm{Na}_{2} \mathrm{O}$, independentemente dos teores de $\mathrm{SiO}_{2}$, e os diagramas $\mathrm{Na}_{2} \mathrm{O}$ versus $\mathrm{K}_{2} \mathrm{O}$ e $\mathrm{SiO}_{2}$ versus $\mathrm{K}_{2} \mathrm{O}$ classificam a associação como sendo do tipo médio a alto potássio. 
(A)
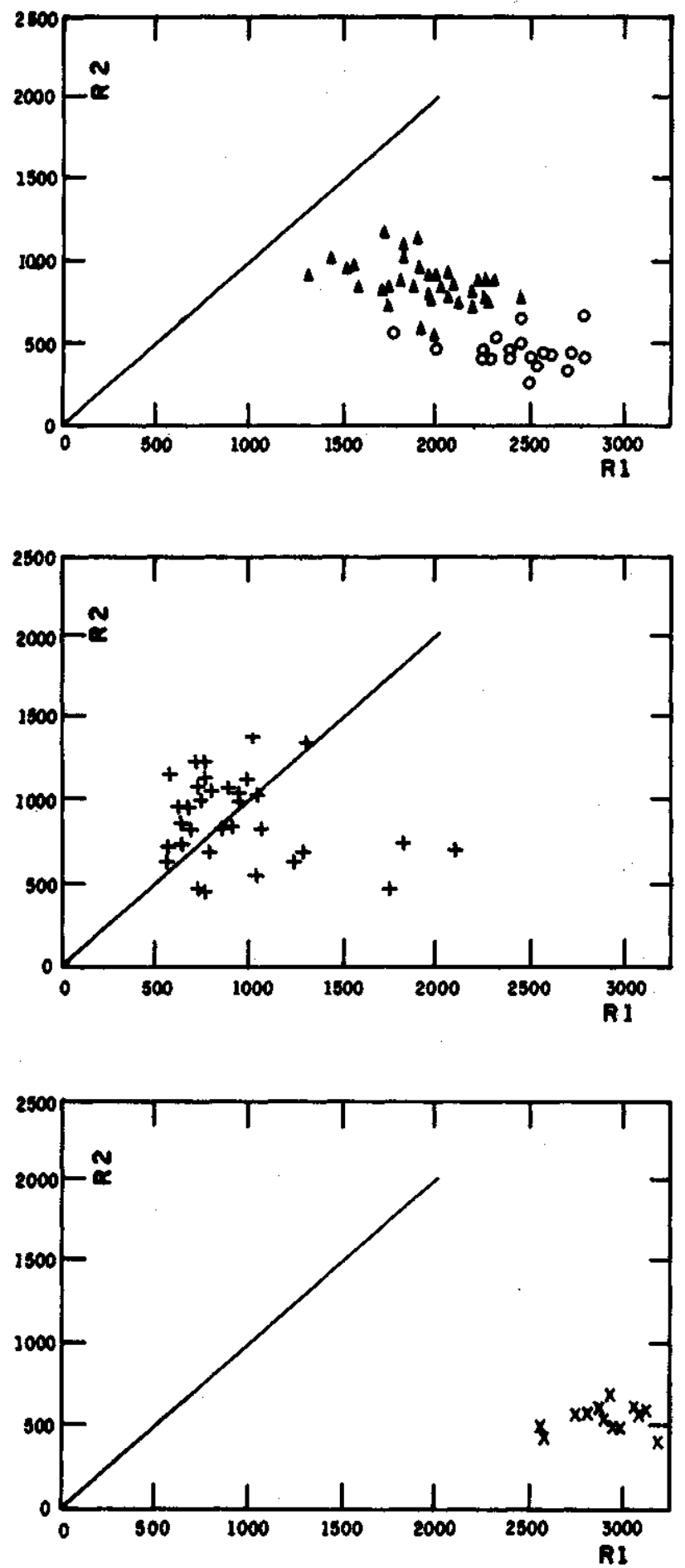

(B)

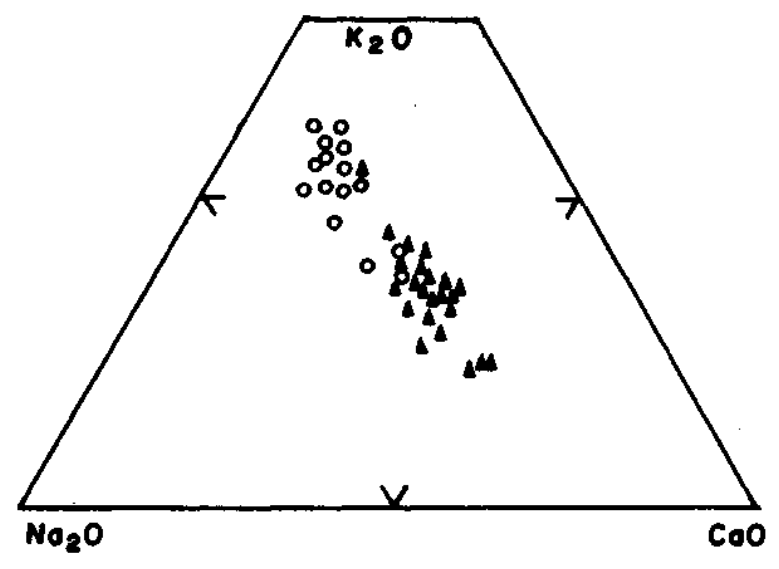

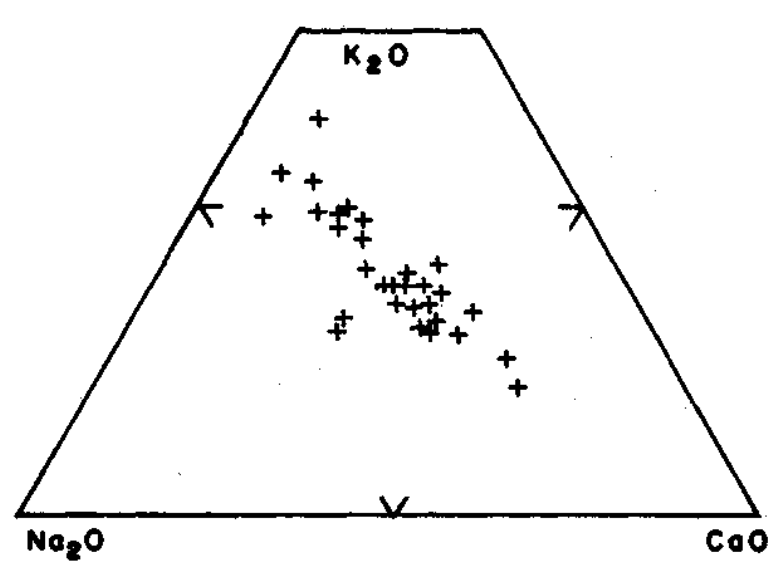

Figura 5 -Diagramas $\mathrm{RI}$ versus $\mathrm{R} 2$ (A, segundo De La Roche et al. 1980) e $\mathrm{K}_{2} \mathrm{O}: \mathrm{Na}_{2} \mathrm{O}: \mathrm{CaO}$ (B, segundo Barker \& Arth 1976) para as associações plutônicas Socorro I ( $\mathbf{\Delta})$, Socorro II (o), Piracaia (+) e Nazaré Paulista ( $x$ )

Figure 5 - RI versus $\mathrm{R} 2$ diagram (A, after De La Roche et al. 1980) and $\mathrm{K}_{2} \mathrm{O}: \mathrm{Na}_{2} \mathrm{O}: \mathrm{CaO}$ diagram (B, after Barker \& Arth 1976) for the plutonic associations Socorro I ( $\boldsymbol{\Delta})$, Socorro II (o), Piracaia (+) and Nazaré Paulista (x)

Associação Socorro II Corresponde a uma suíte de rochas dominantemente epizonais cuja intrusão ocorreu nas rochas da Associação Plutônica Socorro I após o alçamento destas para a aquisição de características rapteis (a fase de rising and unroofing de Pitcher 1978).

As rochas são dominantemente eqüigranulares ao lado de subordinados termos ineqüigranulares e porfiríticos e de composição essencialmente sienogranítica. Bandamentos, estruturas de fluxo e enclaves microgranulares máficos são raros, em oposição aos frequentes xenólitos de rochas da Associação Socorro I. Os contatos entre corpos magmáticos das associações magmáticas Socorro I e Socorro II são frequentemente tectônicos com a ocorrência local de brechas magmáticas. Rochas, em parte equivalentes a Associação Socorro II, foram designadas por Campos Neto et al. (1984b) de Suíte Salmão, que reúne stocks, bossas, plugs e 
outras intrusões menores de rochas equigranulares, normalmente bem delimitadas, que cortam as rochas da Suíte Bragança Paulista.

A mineralogia característica das rochas da Associação Socorro II é essencialmente a mesma da Associação Socorro I. Em termos modais diferem pelo domínio do feldspato alcalino (microclínio), por maiores teores de quartzo, pela raridade ou ausência de hornblenda e por um índice de coloração menor. Quimicamente apresenta menor variabilidade em relação à Associação Socorro I (Fig. 2). Os diagramas das figuras 3,4 e 5 ressaltam a existência de uma descontinuidade composicional mais ou menos acentuada entre as associações Socorro I e Socorro II. Esta é mais rica em sílica, álcalis e potássio (diagramas $\mathrm{SiO}_{2}$ versus $\mathrm{Na}_{2} \mathrm{O}+\mathrm{K}_{2} \mathrm{O}$ e $\mathrm{SiO}_{2}$ versus $\mathrm{K}_{2} \mathrm{O}$ ), apresenta aproximadamente os mesmos teores de sódio (diagrama $\mathrm{SiO}_{2}$ versus $\mathrm{N}^{\wedge} \mathrm{O}$ ) e para teores equivalentes de sódio a Associação Socorro II é mais rica em potássio (diagrama $\mathrm{Na}_{2} \mathrm{O}$ versus $\mathrm{K}_{2} \mathrm{O}$ ). $\mathrm{O}$ conjunto dos diagramas $\mathrm{R}_{1}$ versus $\mathrm{R}_{2}, \mathrm{CaO}: \mathrm{Na} 2 \mathrm{O}: \mathrm{K}_{2} \mathrm{O}, \mathrm{SiO}_{2}$ versus $\mathrm{K}_{2} \mathrm{O}$ e $\mathrm{Na}_{2} \mathrm{O}$ versus $\mathrm{K}_{2} \mathrm{O}$ classifica a Associação Socorro II como sendo cálcio-alcalina de alto potássio.

Associação Piracaia Corresponde a uma suíte granitóide constituída essencialmente por monzonitos, quartzo monzonitos, monzodioritos, quartzo monzodioritos, dioritos e quartzo dioritos, ao lado de sienitos e quartzo sienitos que localmente gradam para monzogranitos. Em alguns casos, as rochas mais evoluídas ocorrem em um complexo sistema de veios anastomosados que cortam as rochas mais máficas. As rochas são de texturas equigranulares (finas, médias, grossas), ineqüigranulares e porfiríticas. É característica a grande variabilidade litológica em pequenas áreas de ocorrência e sua colocação em rochas encaixantes rúpteis e semirúpteis. A sua mineralogia inclui plagioclásio, feldspato alcalino (microclínio), biotita, hornblenda (incluindo hastingsita com ferro tardia), augita e raro hiperstênio (principalmente nos monzonitos). Os minerais acessórios incluem opacos, titanita, zircão e apatita

Descrições detalhadas são devidas a Campos Neto \& Artur (1983), Janasi (1986), Janasi \& Ulbrich (1987) e Artur et al (1 $991 \mathrm{~b})$ e dados modais são apresentados por Janasi (1986) e Artur et al (1991b). Janasi (1986), baseado em apenas 14 análises químicas (incluindo quatro análises de Campos Neto et al. 1983) e utilizando essencialmente diagramas de Harker, definiu a Associação Piracaia como sendo alcalina rica em potássio e com características semelhantes à série granitóide "alcalina" de Lameyre \& Bowden (1982). Entretanto, os dados, quando lançados em diagramas correntes de caracterização de séries magmáticas, mostram ampla dispersão atribuída pelo autor a possíveis problemas analíticos. Janasi (1986) apresenta, igualmente, dados químicos para parte da mineralogia da Associação Piracaia (plagioclásios, feldspatos alcalinos, anfibólios, biotitas verdes e marrons, além de oito e clinopiroxênios) que, tendo por base a sua tipologia de zircão, foi definida por Artur et al (no prelo) como pertencente à série "subalcalina potássica" de Pupin (1980).

Face aos escassos dados químicos disponíveis, foram realizadas 30 novas análises químicas (Tab. 1) que, conjuntamente com as já disponíveis, estão representadas nas figuras 2,3 e 4 . As novas análises químicas foram executadas no Institui für Allgemeine und Augwandte Geologie da Universidade de Munique, R. F. da Alemanha, por métodos correntes de FRX descritos pelo autor das análises (HahnWeinheimer et al 1984).

$\mathrm{O}$ diagrama $\mathrm{SiO}_{2}$ versus $\left(\mathrm{Na}_{2} \mathrm{O}+\mathrm{K}_{2} \mathrm{O}\right)$ caracteriza a Associação Piracaia como uma série alcalina transicional do tipo alto potássio (diagramas $\mathrm{Na}_{2} \mathrm{O}$ versus $\mathrm{K}_{2} \mathrm{O}$ e $\mathrm{SiO}_{2}$ versus $\left.\mathrm{K}_{2} \mathrm{O}\right)$. O Na $2 \mathrm{O}$ e o $\mathrm{K}_{2} \mathrm{O}$ apresentam nítida correlação com
$\mathrm{SiO}_{2}$ e no diagrama $\mathrm{R}$, versus $\mathrm{R}_{2}$ as amostras situam-se dominantemente a esquerda da bissetriz do diagrama, configurando afinidades shoshoníticas no sentido de Pagel \& Leterrier(1980).

Associação Nazaré Paulista Corresponde a uma suíte que reúne rochas essencialmente equigranulares de granulação fina a média e de composição variando entre granodiorítica e sienogranítica (Campos Neto et al 1984a, Wernick et al 1987). As rochas são bastante quartzosas e geralmente portadoras de biotita e granada ao lado de ocasional muscovita, sillimanita e cordierita. A granada ocorre tanto sob a forma de grãos isolados quanto manteada por biotita, em agregados intercrescidos com biotita e quartzo ou ocupando o centro de pequenas manchas hololeucocráticas quartzo feldspáticas desprovidas, inclusive, de opacos. Também o quartzo pode ocorrer manteado por biotita.

O "magma Nazaré Paulista" resulta da anatexia de granada-biotita-sillimanita-cordierita gnaisses do Grupo Itapira. $\mathrm{Na}$ localidade homónima, este processo pode ser observado em todos os estágios evolutivos, desde a formação de migmatitos acamadados, dobrados, flebíticos e nebulíticos até a geração de núcleos de mobilizados maiores autóctones, parautóctones ou francamente discordantes.

As figuras 2, 3, 4 e 5 ressaltam o caráter silicoso da Associação Nazaré Paulista, os teores algo mais baixos de $\mathrm{Na}_{2} \mathrm{O}$ em relação às demais associações plutônicas aqui consideradas e sua posição particular no diagrama $\mathrm{CaO}: \mathrm{K}_{2} \mathrm{O}: \mathrm{Na}_{2} \mathrm{O}$.

\section{SEQUÊNCIA TEMPORAL DE COLOCAÇÃO DAS} ASSOCIAÇÕES PLUTÔNICAS A sequểncia temporal de colocação das quatro associações plutônicas integrantes do Complexo Granitóide Socorro foi estabelecida em virtude de três referências: 1. fases tectônicas regionais; 2. relações de contatos entre as associações plutônicas; e 3. dados geocronológicos. Estes são ainda muito esparsos e de caráter regional, servindo, portanto, apenas como referencial genérico. A figura 6 resume a análise da sequência de colocação das associações plutônicas do Complexo Granitóide Socorro, tanto suas relações com as distintas fases dos períodos da tectônica de cavalgamento, transcorrência e normal presentes na área aqui considerada (Artur et al 1991 b) quanto nas relações dos contatos entre as diversas associações plutônicas conforme descritas por Artur et al (1991a). Os dados geocronológicos suportam, indicativamente, o quadro tectono-magmático evolutivo da figura 6. Dados $\mathrm{Rb} /$ $\mathrm{Sr}$ em migmatitos do embasamento regional (Artur 1980, Wernick et al 1981, Artur et al 1990) situam a anatexia do Ciclo Brasiliano entre 650 e $550 \mathrm{Ma}$, destacando a longa duração do processo (é provável que tenha sido seguidamente retomado por meio de sucessivos impulsos térmicos). À esta anatexia associa-se a geração dos "magmas Nazaré Paulista" num processo gradual, ora "congelado" em migmatitos expostos ao longo das rodovias SP-65 e BR-381 na área considerada. A idade de uma isócrona $\mathrm{Rb} / \mathrm{Sr}$ de referência para a Associação Piracaia, baseadas em amostras de uma área afetada pelo período de transcorrência, revela idade de $580 \pm 13$ Ma (Janasi \& Ulbrich 1987). Em algumas zonas de transcorrência que afetam o Complexo Piracaia observa-se, localmente, a penetração de filetes e veios de rochas da Associacão Nazaré Paulista, indicando a existência de uma fase de geração de "magmatismo Nazaré Paulista" posterior ao início da colocação da Associação Piracaia. Neste mesmo período de transcorrência, nas imediações de Atibaia (Serra Caetetuba), rochas da Associação Nazaré Paulista também cortam rochas da Associação Socorro I. Na Associação Socorro I, um hornblenda monzogranito porfiróide afetado pela fase tardia do período 
Tabela 1 -Análises químicas (elementos maiores, em \% de peso, e traços, em ppm) de 30 amostras da Associação Piracaia por FRX. Analista Klaus Weber-Diefenbach

Table 1 - Chemical analysis (major, in weight \%, and trace elements, in ppm) of 30 samples from the Piracaia Plutonic Association by FRX. Analist Klaus Weber-Diefenbach

Amostras pir-15 pir-20 pir-29 pir-12 pir-1 pir-23 pir-13a pir-8 pir-7 pir-28 pir-25 pir-23a pir-14 pir-9 pir-16

\begin{tabular}{|c|c|c|c|c|c|c|c|c|c|c|c|c|c|c|c|}
\hline $\mathrm{iO}_{2}$ & 47,48 & 48,33 & 49,80 & 50,43 & 51,90 & 52,13 & 52,51 & 52,64 & 52,66 & 52,71 & 52,80 & 52,91 & 53,02 & 53,30 & 53,39 \\
\hline$U_{2}$ & 2,18 & 2,25 & 1,74 & 2,69 & 1,62 & 1,94 & 1,71 & 1,81 & 1,81 & 1,55 & 1,54 & 1,86 & 1,41 & 1,78 & 1,44 \\
\hline $\mathrm{l}_{2} \mathrm{O}_{3}$ & 17.01 & 18,38 & 17,70 & 15,07 & 18,30 & 17,78 & 18,02 & 18,03 & 18,53 & 18,06 & 18,23 & 17,97 & 18,50 & 17,66 & 17,99 \\
\hline $\mathrm{e}_{2} \mathrm{O}_{3}(\mathrm{t})$ & 13,05 & 10,56 & 10,40 & 12,30 & 9.02 & 8,91 & 8,83 & 9,22 & 8.59 & 8,70 & 8,60 & 8,43 & 8.86 & 9,17 & 9,23 \\
\hline InO & 0.22 & 0,18 & 0,17 & 0,1 & 0,17 & 0,16 & 0,17 & 0,16 & 0,16 & 0,16 & 0,16 & & 0,16 & 0,16 & 0,17 \\
\hline IgO & 5,1 & 4,27 & 3,90 & 4,39 & 3,18 & 18 & 3,14 & 3,11 & 2,87 & 3, & & & 2,78 & 3,06 & 2,84 \\
\hline 0 & 6.00 & 7,47 & 6,35 & 7,51 & 5,60 & 5,69 & 5,70 & 5,09 & 5,38 & 5,50 & 5,49 & 5,50 & 5,11 & 5,04 & 4,46 \\
\hline $\mathrm{Ia}_{2} \mathrm{O}$ & 2,88 & 2,93 & 3,63 & 2,88 & 3,90 & 4,08 & 3,96 & 3,07 & 3,89 & 3,91 & 3,89 & 4,24 & 3,68 & 3,14 & 3,74 \\
\hline $\mathrm{K}_{2} \mathrm{O}$ & 4,50 & 3,57 & 4,14 & 2,80 & 4,48 & 4,14 & 4,49 & 5,40 & 4,90 & 4,62 & 4,66 & 4,16 & 5,10 & 5,43 & 5,19 \\
\hline${ }_{2} \mathrm{O}_{5}$ & 0,02 & 1,50 & 1,74 & 1,33 & 1,36 & 1,15 & 0,96 & 1,22 & 1,16 & 1,24 & 1,20 & 1,04 & 1,04 & 1,11 & 1,21 \\
\hline & 1,20 & 0,60 & 1,20 & 0,55 & 0,96 & 1,30 & 0,90 & 0,89 & 0,29 & 1,20 & 1,20 & 1,40 & 1,10 & 0.90 & \\
\hline
\end{tabular}

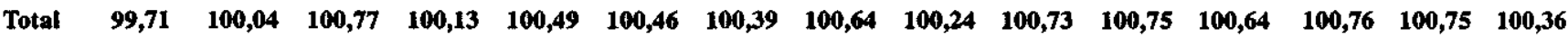

\begin{tabular}{|c|c|c|c|c|c|c|c|c|c|c|c|c|c|c|c|}
\hline $\mathrm{Cr}$ & 9 & 1 & - & 27 & 12 & 5 & 1 & 2 & 12 & - & 1 & 4 & 4 & 3 & 3 \\
\hline $\mathrm{Ni}$ & 15 & 2 & - & 24 & 1 & 4 & 0 & 4 & 3 & - & 2 & 7 & 3 & 2 & 4 \\
\hline Co & 43 & 34 & - & 38 & 25 & 25 & 28 & 25 & 28 & - & 26 & 25 & 25 & 25 & 30 \\
\hline Sc & 11 & 12 & - & 20 & 7 & 8 & 6 & 8 & 7 & - & 7 & 7 & 8 & 5 & 8 \\
\hline V & 26 & 24 & - & 168 & 14 & 101 & 54 & 73 & 57 & - & 49 & 251 & 58 & 57 & 94 \\
\hline $\mathrm{Cu}$ & 974 & 1020 & - & 18 & 2 & 6 & 27 & 9 & 7 & - & 247 & 1390 & 502 & 10 & 418 \\
\hline $\mathrm{Pb}$ & 15 & 10 & - & 17 & 34 & 14 & 33 & 31 & 40 & - & - & 2 & 8 & 28 & 9 \\
\hline $\mathrm{Zn}$ & 1900 & 1950 & - & 121 & 76 & 2850 & 70 & 96 & 74 & - & 273 & 2200 & 973 & 89 & 812 \\
\hline $\mathbf{R b}$ & 128 & 122 & - & 62 & 104 & 93 & 107 & 132 & 119 & - & 116 & 91 & 126 & 133 & 131 \\
\hline $\mathrm{Ba}$ & 3750 & 4210 & - & 1610 & 5810 & 6320 & 5010 & 2120 & 3620 & - & 3580 & 4090 & 2230 & 3580 & 1800 \\
\hline St & 477 & 721 & - & 746 & 1100 & 549 & 1370 & 766 & 985 & - & 803 & 554 & 642 & 810 & 458 \\
\hline Ga & 235 & 259 & - & 23 & 19 & 391 & 20 & 22 & 18 & - & 34 & 32 & 143 & 21 & 119 \\
\hline $\mathrm{Ta}_{\mathbf{a}}$ & 5,10 & 2,41 & - & 10,70 & 8,93 & 2,35 & 9,96 & 7,57 & 7,27 & - & 6,96 & 6,18 & 5,40 & 14,50 & 9,95 \\
\hline $\mathrm{Nb}$ & 16,0 & 92,7 & - & 14,1 & 70,0 & 211,0 & 285,0 & 156,0 & 53,4 & - & 2,6 & 31,4 & 57,3 & 245,0 & 49,3 \\
\hline $\mathrm{H}$ & 2,80 & 0,20 & - & 8,68 & 5,18 & 4,89 & 3,05 & 5,02 & 3,90 & - & 4,62 & 3,72 & 0,02 & 8,30 & 7,41 \\
\hline $\mathbf{Z}$ & 372 & 217 & - & 353 & 213 & 449 & 194 & 161 & 187 & - & 452 & 438 & 151 & 372 & 572 \\
\hline & 102 & 131 & & & & & & & & & & & & & \\
\hline
\end{tabular}

\begin{tabular}{|c|c|c|c|c|c|c|c|c|c|c|c|c|c|c|c|}
\hline \multicolumn{2}{|c|}{ Amostras pir-13 } & pir-17 & pir-18 & pir-26 & pir-30 & pir-19 & pir-4 & pir-10 & pir-6 & pir-27 & pir-11 & pir-22 & pir-24 & pir-21 & pir-24s \\
\hline $\mathrm{SiO}_{2}$ & 53.47 & 53,56 & 55,80 & 57,10 & 57,18 & 58,28 & 58.51 & 58,65 & 59,12 & 59,90 & 60,44 & 64,73 & 65,27 & 65,84 & 67, \\
\hline $\mathrm{TiO}_{2}$ & 1.53 & 1.68 & 1,36 & 0,98 & 1,13 & 1,11 & 0,90 & 0,86 & 0,85 & 0,70 & 0,77 & 0,34 & 0,83 & 0,36 & 0 \\
\hline $\mathrm{Al}_{2} \mathrm{O}_{3}$ & 18,49 & 18,83 & 19,25 & 18,53 & 19,09 & 18,57 & 18,63 & 18,38 & 19,19 & 18,09 & 18,25 & 17,62 & 15,82 & 16,98 & 15 \\
\hline $\mathrm{Fe}_{2} \mathrm{O}_{3}(\mathrm{t})$ & 8,43 & 7,99 & 6,75 & 6,60 & 6,90 & 5,88 & 6,05 & 5,50 & 5,88 & 5,84 & 5,01 & 2.77 & 4,55 & 2,40 & 4 , \\
\hline $\mathrm{MnO}$ & 0,16 & 0,15 & 0,13 & 0,14 & 0,14 & 0,12 & 0,15 & 0,15 & 0,15 & 0,15 & 0,11 & 0,08 & 0,07 & 0,09 & 0,0 \\
\hline $\mathrm{MgO}$ & 2,85 & 2,86 & 2,23 & 1,40 & 1,91 & 1,65 & 1,10 & 1,10 & 1,11 & 0,75 & 1,05 & 0,31 & 0,54 & 1,00 & 0,4 \\
\hline $\mathrm{CaO}$ & 5,04 & 5,64 & 4,61 & 3,78 & 3,30 & 3,45 & 2,66 & 2,79 & 2,73 & 2,20 & 2,52 & 1,23 & 1,13 & 1,12 & 0, \\
\hline $\mathrm{Na}_{2} \mathrm{O}$ & 4,10 & 3,78 & 3,99 & 4,49 & 3,81 & 4,16 & 4,53 & 4,49 & 4,53 & 4,76 & 4,34 & 4,66 & 4,58 & 4,03 & 4 , \\
\hline $\mathbf{K}_{2} \mathrm{O}$ & 4,56 & 4,27 & 4,93 & 5,92 & 5,78 & 5,89 & 6,54 & 6,79 & 6,53 & 6,76 & 6,65 & 6,43 & 6,28 & 7,60 & 6. \\
\hline $\mathrm{P}_{2} \mathrm{O}_{3}$ & 0,90 & 0,83 & 0,63 & 0,45 & 0,55 & 0,50 & 0,34 & 0,32 & 0,31 & 0,22 & 0,29 & 0,06 & 0,42 & 0,50 & 0,3 \\
\hline P.F. & 0,90 & 0,90 & 1,10 & 1,00 & 1,00 & 1,00 & 1,45 & 0,90 & 0,50 & 0,80 & 0,90 & 1,10 & 1,00 & 0,70 & 0,7 \\
\hline
\end{tabular}

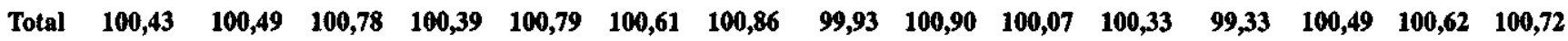

\begin{tabular}{|c|c|c|c|c|c|c|c|c|c|c|c|c|c|c|c|}
\hline $\mathrm{Cr}_{\mathbf{r}}$. & 8 & 1 & 2 & 14 & - & 3 & 14 & 15 & 13 & - & 13 & - & - & - & - \\
\hline $\mathrm{Ni}$ & 1 & 1 & 2 & 13 & - & 2 & 6 & 9 & 7 & - & 5 & - & - & - & - \\
\hline $\mathrm{Co}$ & 28 & 26 & 23 & 20 & - & 23 & 18 & 15 & 17 & - & 13 & - & - & - & - \\
\hline Sc & 5 & 6 & 4 & 1 & - & 3 & 5 & 6 & 3 & - & 3 & - & - & - & - \\
\hline V & 6 & 85 & 42 & 11 & - & 38 & 98 & 92 & 110 & - & 76 & - & - & - & - \\
\hline $\mathrm{Cu}$ & 8 & 1820 & 1620 & 121 & - & 1130 & 3 & 9 & 2 & - & 18 & - & - & - & - \\
\hline $\mathrm{Pb}$ & 35 & 15 & 10 & 15 & - & 0 & 34 & 32 & 32 & - & 34 & - & - & - & - \\
\hline $\mathrm{Zn}$ & 76 & 3370 & 2810 & 78 & - & 1980 & 87 & 78 & 77 & - & 68 & - & - & - & - \\
\hline Rb & 109 & 96 & 105 & 146 & - & 119 & 133 & 127 & 127 & $=$ & 132 & - & - & - & - \\
\hline $\mathrm{Ba}$ & 2370 & 7820 & 6410 & 1800 & - & 4580 & 1700 & 2010 & 1900 & - & 1960 & - & - & - & - \\
\hline Sr & 1470 & 938 & 779 & 426 & - & .469 & 350 & 428 & 415 & - & 416 & - & - & - & - \\
\hline $\mathrm{Ga}$ & 20 & 482 & 421 & 6 & - & 300 & 19 & 19 & 19 & - & 20 & - & - & - & - \\
\hline $\mathbf{T a}$ & 11,90 & 3,70 & 5,21 & 7,53 & - & 5,74 & 13,10 & 15,70 & 18,50 & - & 19,10 & - & - & - & - \\
\hline $\mathrm{Nb}$ & 146,0 & 208,0 & 174,0 & 17,10 & - & 129,0 & 32,2 & 44,0 & 45,0 & - & 40,5 & - & - & - & - \\
\hline Hf & 3,92 & 0,80 & 0,20 & 7,45 & - & 1,00 & 13,60 & 12,10 & 13,80 & - & 14,90 & - & - & - & - \\
\hline $\mathrm{Zr}_{\mathbf{r}}$ & 207 & 237 & 205 & 548 & - & 263 & 567 & 501 & 571 & - & 626 & - & - & - & - \\
\hline Y & 62 & 229 & 183 & 14 & - & 115 & 70 & 49 & 45 & - & 48 & - & - & - & - \\
\hline
\end{tabular}


de cavalgamento tem idade de $655 \pm 2 \mathrm{Ma}$ (U/Pb em zircões; Ebert, informação verbal), e um monzogranito cristalizado durante o período de transcorrência revelou idade de $595 \pm$ $12 \mathrm{Ma}$ (U/Pb em zircões; Ebert informação verbal). Datação, também $\mathrm{U} / \mathrm{Pb}$ em zircões de hornblenda granito porfiróide com idade de $635 \pm 10$ Ma (Tassinari, informação verbal), ocupa posição intermediária entre as referidas idades. Já, a Associação Socorro II tem idade Rb/Sr entre 550 e 500 Ma (Wernick et al 1976, Vlach \& Cordani 1986, Artur 1988). Entretanto, o isocronismo parcial entre as associações Socorro I e Socorro II pode ser observado na Pedreira Atibaia, localizada nas proximidades da cidade homónima, onde ocorrem misturas magmáticas entre estas associações durante o período de cavalgamento.

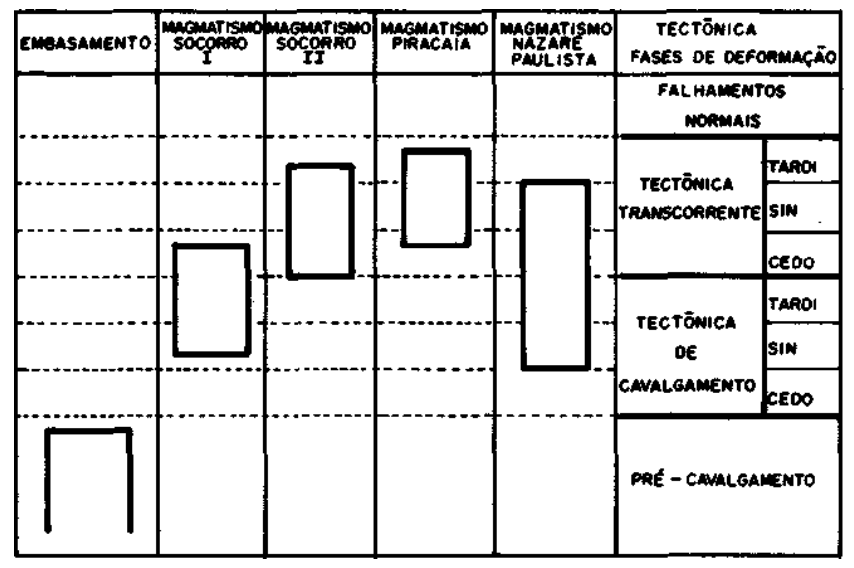

Figura 6 - Evolução do magmatismo do Complexo Granitóide Socorro em relação às fases de deformações regionais, segundo Artur et al. (1991a), simplificado Figure 6 - Magmatic evolution of the Socorro Granitoid Complex in relation to the regional deformation phases, after Artur et al. (1991a), simplified

\section{O COMPLEXO SOCORRO E A EVOLUÇÃO GEODI-} NÂMICA REGIONAL Em relação ao Complexo Granitóide Socorro, cabe destacar:

- O seu posicionamento geográfico. O complexo situa-se em uma área mais intensamente afetada pela convergência e colisão entre os Blocos Paraná e São Francisco (Davino 1979, Soares et al 1990, Zanardo 1992);

- A sua natureza plurisserial. O complexo é o resultado da coalescência de quatro associações plutônicas distintas que recortam a convergência entre os Blocos Paraná e São Francisco (retratado pela Associação Socorro I), a sua colisão (representado pela Associação Nazaré Paulista), o soerguirnento pós-colisional (assinalado pela Associação Socorro II) e a implantação progressiva de condições de estabilização (indicadas pela Associação Piracaia). Todas as associações constituem, regionalmente, tanto numerosos corpos intrusivos monosseriais quanto corpos plurisseriais mais ou menos complexos;

- O magmatismo que representa esta associação regional tem a duração da ordem de 150 Ma como atestam os dados geocronológicos de Artur (1980), Wernick et al. (1981), Artur et al (1988), Janasi \& Ulbrich (1987), Wernick et al (1976), Vlach \& Cordani (1986) e Artur (1988) para as diferentes associações magmáticas do Complexo Granitóide Socorro ou seus equivalentes ao nível regional;

- Os períodos tectônicos de cavalgamento, transcorrência e de falhamentos normais que retratam a evolução geodinâmica ao nível regional (Soares et al 1990, Wernick 1990, Zanardo 1992) estão preservados no Complexo Granitóide Socorro (Wernick 1967, Campos Neto et al 1984a), onde cada período pode ser subdividido em diferentes fases (Artur et al 1991a, b).

- Neste processo de convergência e colisão de blocos crustais seguidas de seu soerguirnento, relaxamento e estabilizaç̃o, as associações Socorro I e Socorro II podem ser consideradas como o resultado de processos magmatogênicos aluando sobre um mesmo protólito mantélico progressivamente desidratado, conforme o modelo de Bonin (1987). A Associação Nazaré Paulista resulta de magmas gerados pela fusão de protólitos crustais dominantemente metassedimentares e a Associação Piracaia é o fruto da anatexia de protólitos mantélicos férteis.

- A subducção do Bloco São Francisco por debaixo do Bloco Paraná, como sugerido por Davino (1979) e Zanardo (1992), implica, atualmente, na exposição de níveis crustais cada vez mais profundos do Bloco Paraná em direção à sutura. Este aspecto reflete a ocorrência de rochas cálcioalcalinas hidratadas a oeste do Complexo Granitóide Socorro, na presença de rochas cálcio-alcalinas hidratadas e anidras (charnockíticas) no mesmo (Wernick et al 1984a) e de rochas cálcio-alcalinas essencialmente charnockíticas mais a leste do Complexo Granitóide Socorro (Artur 1988, Wernick et al 1988a).

- A sequência temporal da colocacãa das distintas associações plutônicas do Complexo Granitóide Socorro indica que o magmatismo que caracteriza os sucessivos estágios da evolução geodinâmica regional, não correspondem a fenómenos temporalmente estanques. Ao contrário, mostram uma superposição temporal parcial que retraia a transição gradual entre os sucessivos estágios geodinâmicos.

CONCLUSÕES 1. O Complexo Granitóide Socorro situa-se geograficamente em uma área afelada pela convergência e colisão enlre as Placas São Francisco e Paraná.

2. O complexo mosira-se afelado pêlos períodos lectônicos de cavalgamento, transcorrência e de falhamenlos normais que ao nível regional se associam à convergência final, colisão e posterior relaxamento enlre os blocos São Francisco e Paraná.

3. O Complexo Granitóide Socorro é uma entidade magmálica plurisserial formado pela agregação de qualro associações magmáticas dislinlas (Socorro I, Socorro II, Nazaré Paulisla e Piracaia). As associações são o resullado de processos magmatogênicos aluando sobre protólitos distintos dados lanlo por rochas cruslais quanto manlélicas, férteis ou não.

4. As qualro associações plulônicas compreendem boa parte da evolução magmálica regional ocorrida, grosseiramente, no intervalo enlre 650 e 500 Ma alrás.

5. As qualro associações plulônicas coadunam-se com a evolução geodinâmica regional. Assim, a Associação Socorro I (cálcio-alcalina, médios a altos teores de $\mathrm{K}_{2} \mathrm{O}$ ) pode ser relacionada com a fase de convergência enlre os Blocos Paraná e São Francisco; a Associação Nazaré Paulisla (cruslal, peraluminosa) com o período de colisão enlre os mesmos; a Associação Socorro II (cálcio-alcalina, altos teores de $\mathrm{K}_{2} \mathrm{O}$ ) com o soerguimenlo lardi/pós-colisional e a Associação Piracaia (alcalina polássica) possivelmente com o estágio de relaxamento pós-colisional.

6. As associações plutônicas mostram uma superposição temporal dos seus períodos de colocação que reflete a iransição gradual enlre os sucessivos eslágios da evolução geodinâmica regional no lapso de tempo aqui considerado.

Agradecimentos $\mathrm{Os}$ autores agradecem ao $\mathrm{CNPq}$ (Processos 500213/91-7 e 300319/81-9) e a FINEP (Processo 4.3.90.0315.00) pelo apoio dado para a realizaçẫo deste trabalho. Agradecem, igualmente, aos "revisores anónimos" que, com críticas e sugestões, contribuíram para o aprimoramento do texto final. 


\section{REFERÊNCIAS BIBLIOGRÁFICAS}

ARTUR, A.C. 1980. Rochas Metamórficas dos Arredores de Itapira - SP. São Paulo. 193 p. (Dissertação de Mestrado, IG-USP).

ARTUR, A.C. 1988. Evolução Policíclica da Infra-Estrutura da Porção Sul do Estado de Minas Gerais e Regiões Adjacentes do Estado de São Paulo. São Paulo. 231 p. (Tese de Doutoramento, IG-USP).

ARTUR, A.C.; WERNICK, E.; KAWASHITA, K. 1988. Geocronologia das unidades litoestratigráficas do embasamento cristalino da região sul de Minas Gerais e regiões adjacentes do Estado de São Paulo. In: CONGR. BRÁS. GEOL., 35. Belém, 1988. Anais... Belém, SBG. v. 6, p. 2854-2869.

ARTUR, A.C.; WERNICK, E.; KAWASHITA, K. 1990. Migmatitos policíclicos do sul de Minas Gerais e áreas adjacentes do Estado de São Paulo: caracterização estrutural-petrográfica e dados geocronológicos. In: CONGR. BRÁS. GEOL., 36. Natal, 1990. Anais... Natal, SBG. v. 6, p. 2827-2843.

ARTUR, A.C.; EBERT, H.D.; WERNICK, E. 1991a. Magmatismo e tectônica no Complexo Socorro (SP/MG). In: SIMP. GEOL. DO SUDESTE, 2. São Paulo, 1991. Atas... São Paulo, SBG/NSP-RJ. p. $105-112$.

ARTUR, A.C; EBERT, H.D.; ANGELI, N · RUEDA, J.R.J; MANIAKAS, S. 1991b. Mapeamento Geológico em 1:50.000 da Quadrícula Extre$m a$. Local, Convénio PRO-MINERIO/IGCE-UNESP. v. 1, 152 p. (Relatório Final).

ARTUR, A.C.; WERNICK, E.; SOUZA, S.C.A.; WEBER-DIEFENBACH, K. 1994. Tipologia de zircão e quimismo do complexo monzonítico-monzodiorítico Piracaia, SP. Geociências, 13(2): (No prelo).

BARKER, J.G. \& ARTH, F. 1976. Rare-Earth partitioning between hornblende and dacitic liquid and implication for the génesis of trondhjemitic-tonalitic magmas. Geology, 4:534-536.

BONIN, B. 1987. From orogenic to anorogenic magmatism: a petrological model for the transition calc-alkaline - alkaline complexes. Rev. Brás. Geoc., 17(4):366-371.

CAMPOS NETO, M.C. \& ARTUR A.C. 1983. A suíte quartzo monzonítica a diorítica de Piracaia, SP. In: SIMP. REG. GEOL., 4. São Paulo, 1983. Atas... São Paulo, SBG-NSP. p. 47-60

CAMPOS NETO, M. C.; BASEI, M.A.S.; ARTUR, A.C.; SILVA, M.E.; MACHADO, R.; DIAS NETO, C.M.; FRAGOSO-CESAR, A.R.; SOUZA A.P. 1983. Geologia das Folhas Piracaia e Igaratá. In: JORNADA DA CARTA GEOLÓGICA DO ESTADO DE SÃO PAULO EM 1:50000, 1. São Paulo Pró-Minério/IPT. p. 55-79.

CAMPOS NETO, M.C.; BASEI, M.A.S.; ALVES, F.R.; VASCONCELLOS, A.C.B. 1984a. A nappe de cavalgamento Socorro (SPMG). In: CONGR. BRÁS. GEOL., 33. Rio de Janeiro, 1984. Anais... Rio de Janeiro, SBG. v. 4, p. 1809-1822.

CAMPOS NETO, M.C.; FIGUEIREDO, M.C.H.; BASEI, M.A.S.; ALVES, F.R. 1984b. Os granitóides da região de Braganca Paulista, SP. In: CONGR. BRAS. GEOL., 33. Rio de Janeiro, 1984. Anais... Rio de Janeiro, SBG. v. 6, p. 2854-2862.

DAVINO, A. 1979. O baixo gravimétrico da região de Caldas Novas, Goiás. In: SIMP. REG. GEOL., 2. Rio Claro, 1979. Atas... São Paulo, SBG-NSP. p. 87-100.

DE LA ROCHE, H.; LETERRIER, J; GRANDCLAUDE, P; MARCHAL, M. 1980. A classification of volcanic and plutonic rocks using $R, R_{2}-$ diagram and major-element analyses - its relationships with current nomenclature. Chem. Geol., 29:183-210.

HAHN-WEINHEIMER, P; HIRNER, A.; WEBER-DIEFENBACH, K. 1984. Grundlagen und Praktische Anwendung der Rõntgenfluorezenzanalyse (RFA). Braunschweiz Wiesbaden, Fried. Vieweg \& Sohn. $252 \mathrm{p}$

JANASI, V.A. 1986. Geologia e Petrologia do Maciço Monzodiorítico Monzonítico de Piracaia. São Paulo. 281 p. (Dissertação de Mestrado, IG-USP).

JANASI, V.A. \& ULBRICH, H.G.J. 1987. Petrogenesis of the monzodioritic Piracaia Massif, State of São Paulo, southern Brasil: field and petrographic aspects. Rev. Brás. Geoc., 17(4):524-534.

LAMEYRE, J. \& BOWDEN, P. 1982. Plutonic rock type series: discrimination of various granitoid series and related rocks. $J$. Volcanol. Geotherm. Res., 14:169-186.

LÊ MAITRE, R.W. (ed.) 1989. A Classiflcation of Igneous Rocks and Glossary of Terms. Recommendation of the IUGS Subcommission on Systematic of Igneous Rocks. Blackwell, Oxford. 193 p.
PAGEL, M. \& LETERRIER, J. 1980. The subalkaline potassic magmatism of the Ballons Masssif (Southern Vosges, France): shoshonitic affmity. Lithos, 13:1-10.

PECCERILLO, A. \& TAYLOR, S.R. 1976. Geochemistry of Eocene calcalkaline volcanic rocks from the Kastamonu área, northern Turkey. Contrib. Mineral. Petrol., 58:63-81.

PITCHER, W.S. 1978. The anatomy of a batholith. J. Geol. Soe. London, 135:157-182.

PUPIN. J.P. 1980. Zircon and granite petrology. Contrib. Mineral. Petrol., 73:207-220.

SOARES, P.C.; FIORI, A.P.; CARVALHO, S.G. 1990. Tectônica colisional oblíqua entre o Bloco Paraná e a margem sul do Cráton São Francisco, no Maciço Guaxupé. In: CONGR. BRÁS. GEOL., 33. Natal, 1990. Anais... Natal, SBG. v. 7 p. 63-79.

VLACH, S.R.F. 1993. Geologia e Petrologia dos Granitóides de Morungaba, SP. São Paulo. 414 p. (Tese de Doutoramento, IG-USP).

VLACH, S.R.F. \& CORDANI, U.G. 1986. A sistemática Rb/Sr em rochas granitóides: considerações interpretativas, limitações e exemplos brasileiros. Rev. Brás. Geoc., 16(1):38-53.

WERNICK, E. 1967. A Geologia da Região de Amparo, Leste do Estado de São Paulo. Rio Claro. 2 v, 216 p. (Tese de Doutoramento, FFCL/ UNESP).

WERNICK, E. 1990. Zoneamento magmático regional de granitóides brasilianos no Sudeste/Sul do Brasil: implicaçôes geotectônicas. In: CONGR. BRÁS. GEOL., 36. Natal, 1990. Anais... Natal, SBG. v. 4 p. $1668-1683$

WERNICK, E. \& GALEMBECK, T.M.B. 1986. Caracterização do plutonismo granitóide do Ciclo Brasiliano no Estado de São Paulo através do método da tipologia de zircão. In: CONGR. BRAS. GEOL., 34. Goiânia, 1986. Anais... Goiânia, SBG. v. 6, p. 1369-1382.

WERNICK, E.; OLIVEIRA, M.A.F.; KAWASHITA, K.; CORDANI, U.G.; DELHAL, J. 1976. Estudos geocronológicos pelo método $\mathrm{Rb} / \mathrm{Sr}$ no Bloco Jundiaí e áreas vizinhas. Rev. Brás. Geoc., 6(2):125-135.

WERNICK, E; ARTUR, A.C; FIORI, A.P. 1981. Reavaliacão de dados geocronológicos da região nordeste do Estado de São Paulo e unidades equivalentes dos Estados de Minas Gerais e Rio de Janeiro. In: SIMP. REG. GEOL., 3. Curitiba, 1981. Atas... São Paulo, SBG-NSP. v. 1, p. 328-342.

WERNICK, E · DIDIER, J· ARTUR, A.C · HÔRMANN, PK. 1984a. Caracterização da zona marginal charnockítica do Complexo Socorro nos arredores da cidade homónima, SP/MG. In: CONGR. BRÁS. GEOL., 33. Rio de Janeiro, 1984. Anais... Rio de Janeiro, SBG. v. 6, p. 2919-2934.

WERNICK, E; HÔRMANN, P.K; ARTUR, A.C. EULERT, H.F. 1984b. Aspectos petrológicos do Complexo Granítico Socorro (SP/MG): dados analíticos e discussão preliminar. Rev. Brás. Geoc., 14(1):2329.

WERNICK E. DIEFENBACH, K.W; CORREIA, P.R 1987. O granitóide Nazaré Paulista: dados petrográfícos, químicos e de tipologia de zircão. In: SIMP. REG. GEOL., 6. Rio Claro, 1987. Atas... São Paulo, SBG-NSP. v. 1, p. 123-134.

WERNICK, E.; ARTUR, A.C.; VASCONCELLOS, J.P.B.C.; WEBERDIEFENBACH, K. 1988a. Complexos chamockíticos de Ubatuba (SP), Socorro (SP/MG) e do Maciço de Guaxupé (SP/MG); dados litoquímicos, isotópicos e de tipologia de zircão. In: CONGR. LATINO-AMERICANO DE GEOLOGIA, 7. Belém, 1988. Anais... Belém, SBG. p. 544-559.

WERNICK, E; GALEMBECK, TMB; RIGO, L, Jr; WEBER-DIEFENBACH, K.; ARTUR, A.C. 1988b. Séries granitóides e tipologia de zircão. In: CONGR. LATINO-AMERICANO de GEOLOGIA, 7. Belém, 1988. Anais... Belém, SBG. p. 529-543.

ZANARDO, A. 1992. Análise Petrogrâfica, Estratigráfica e Microestrutural da Região de Guaxupé - Passos - Delfinópolis (MG). Rio Claro. 288 p. (Tese de Doutoramento, IGCE-UNESP).

MANUSCRITO A784

Recebido em 31 de agosto de 1994

Revisão do autor em 31 de outubro de 1994 Revisão aceita em 9 de novembro de 1994 